\title{
Study of High Density Lipoprotein Cholesterol among Patients with Acute Coronary Syndrome in Sohag University Hospital
}

\begin{abstract}
Objective: To estimate the prevalence, and impact of high-density lipoprotein cholesterol (HDL-C) on in-hospital outcomes among acute coronary syndrome (ACS) patients in Sohag University Hospital.

Methods: Data were collected prospectively from 273 consecutive patients admitted with a diagnosis of ACS. A low HDL-C was defined as a level $<40 \mathrm{mg} / \mathrm{dL}$ $(1.0 \mathrm{mmol} / \mathrm{L})$ for males and $<50 \mathrm{mg} / \mathrm{dL}(1.3 \mathrm{mmol} / \mathrm{L})$ for females and satisfactory $\mathrm{HDL}-\mathrm{C}$ is defined as a level $\geq 40 \mathrm{mg} / \mathrm{dl}$ for males and $\geq 50 \mathrm{mg} / \mathrm{dl}$ for females.

Results: The overall mean age of the study patients was 58.9_+11.3 years and majority was males (51.4\%). The overall prevalence of low HDL-C was $73.3 \%$ and satisfactory HDL-C was $26.7 \%$. During in-hospital stay and at discharge, the majority were on statin therapy (83.2\%) while $7.7 \%$ were on fibrates. Low HDL-C patients were associated with higher in-hospital mortality than satisfactory HDL-C patients ( $12 \%$ vs. $11 \%$; $\mathrm{p}=0.012$ ) and higher CHF ( $18 \%$ vs. $5.5 \%$; $\mathrm{p}=0.01)$.

Conclusion: ACS patients in Sohag governorate in upper Egypt have a high prevalence of low HDL-C. Insignificantly higher in-hospital mortality and CHF were associated with low HDL-C in women but not in men.
\end{abstract}

Keywords: Lipoportein cholesterol; Coronary syndrome

Research Article
Volume 2 Issue 5 - 2015
Nagwa Ibrahim Thabet ${ }^{1 *}$, Hassan Ahmad
Hassanin ${ }^{2}$ and Yasser Mohamad Kamal ${ }^{3}$
${ }^{1}$ Assistant Lecturer, Aswan University, Egypt
${ }^{2}$ Head of Internal Medicine Department, Sohag University,
Egypt
${ }^{3}$ Lecturer of Internal Medicine, Sohag University, Egypt
*Corresponding author: Nagwa Ibrahim Thabet, Assistant
Lecturer, Aswan Faculty of Medicine, Aswan University,
Egypt, Email: drnagwa185@gmail.com
Received: March 6, 2015 | Published: May 05, 2015

Abbreviations: ACS: Acute Coronary Syndrome; HDL: HighDensity Lipoprotein; STEMI: ST Segment Elevation Myocardial Infarction; NSTE-ACS: Non ST Segment Elevation Acute Coronary Syndrome; CHF: Congestive Heart Failure; PCI: Percutaneous Coronary Intervention; Gulf RACE: Gulf Registry of Acute Coronary Events; ACC: American Cardiac College; MI: Myocardial Infarction; CABG: Coronary Artery Bypass Graft; BMI: Body Mass Index

\section{Introduction}

Acute coronary syndrome (ACS) is a high-risk manifestation of coronary artery disease and represents a substantial proportion of all acute hospitalizations. Although mortality because of ACS has declined in recent years Fox KA et al. [1], largely attributable to optimization of timely reperfusion and innovations in pharmacological therapy, ischemic heart disease remains a leading cause of death and accounted for 7.25 million deaths worldwide in 2008 World Health Organization [2].

High-density lipoprotein (HDL) is one of the major carriers of cholesterol in the blood. It attracts particular attention because, in contrast with other lipoproteins, as many physiological functions of HDL influence the cardiovascular system in favorable ways unless HDL is modified pathologically. The functions of HDL that have recently attracted attention include anti-inflammatory and anti-oxidant activities. High anti-oxidant and antiinflammatory activities of HDL are associated with protection from cardiovascular disease Kontush A et al. [3]. High-density lipoprotein (HDL) is positively associated with decreased risk of coronary heart disease (CHD) As defined by the US National Cholesterol Education Program Adult Treatment Panel III guidelines, an HDL cholesterol level (HDL-C) of $60 \mathrm{mg} / \mathrm{dL}$ or greater is a negative (protective) risk factor Executive Summary of the Third Report of the National Cholesterol Education Program (NCEP) [4]. On the other hand, a high-risk HDL cholesterol level is described as one that is below $40 \mathrm{mg} / \mathrm{dL}$. Randomized, controlled clinical trials have demonstrated that interventions to raise HDL cholesterol levels are associated with reduced CHD events. A prospective analysis by Mora et al. [5] investigated the link between cholesterol and cardiovascular events in women and found baseline HDL-C level was consistently and inversely associated with incident coronary and coronary vascular disease events across a range of low-density lipoprotein-cholesterol (LDL-C) values [5]. While higher HDL levels are correlated with cardiovascular health, no incremental increase in HDL has been proven to improve health. In other words, while high HDL levels might correlate with better cardiovascular health, specifically increasing one's HDL might not increase cardiovascular health Soudijn W [6].

Data from the landmark Framingham Heart Study showed that, for a given level of LDL, the risk of heart disease increases 10 -fold as the HDL varies from high to low. On the converse, however, for a fixed level of HDL, the risk increases 3-fold as LDL varies from low to high Meyers et al. [7]. Even people with very low LDL levels are exposed to increased risk if their HDL levels are not high enough. When is treatment indicated for high cholesterol level? [8,9]. HDL levels below $40 \mathrm{mg} / \mathrm{dL}$ result in an increased risk of coronary artery disease, even in people whose total cholesterol and LDL cholesterol levels are normal. HDL levels between 40 and $60 \mathrm{mg} /$ $\mathrm{dL}$ are considered "normal" Richard NF et al. [10]. However, HDL 
levels greater than $60 \mathrm{mg} / \mathrm{dL}$ may actually protect people from heart disease. Indeed, for several years, doctors have known that when it comes to HDL levels, the higher the better. Low HDL-C Grundy SM et al. [11] and Alberti KG et al. [12] was defined as levels of $<40 \mathrm{mg} / \mathrm{dl}(1.0 \mathrm{mmol} / \mathrm{L})$ for men and $<50 \mathrm{mg} / \mathrm{dl}(1.3 \mathrm{mmol} / \mathrm{L})$ for women. By analogy with the risk associated with low levels of HDL in patients with chronic CVD, low concentrations of HDL-C are an indicator of poor prognosis in patients with ACS. The most conspicuous (but not the only) example is the MIRACL clinical trial (Myocardial Ischemia Reduction with Aggressive Cholesterol Lowering), which randomized 3086 patients with ACS to 16 weeks of treatment with atorvastatin or placebo. In a treatmentadjusted analysis, the levels of HDL-C at the time of diagnosis of ACS predicted the risk of death, repeat infarction, or recurrent angina at 16 weeks Olsson AG et al. [13]. In fact, while low-density lipoprotein cholesterol (LDL-C) levels did not predict CVR, the risk in patients in the upper quartile of HDL-C ( $>53 \mathrm{mg} / \mathrm{dL}$ ) was $62 \%$ lower than in patients in the lower quartile (>_38 mg/dL). In a single-center observational study of 1032 patients with ACS who underwent percutaneous coronary intervention (PCI) and were treated with statins, multivariate analysis showed that the risk of death or a Cardio-vascular event was greater in patients with low HDL-C, both at 1 month and at 1 year of follow-up Wolfram RM et al. [14].

Another study with 320 patients recruited at the point of ACS diagnosis showed that high levels of HDL-C were associated with a lower cardiovascular risk Tziakas DN et al. [15]. The study by Cordero et al. [16] reinforces the evidence for the protective role of HDL-C in patients with chest pain in general. Our registry provided a unique opportunity to study the prevalence, and impact of HDL-C level on in-hospital outcomes among ACS patients in Sohag governorate in Upper Egypt. To our knowledge, there is scant literature on the subject worldwide apart from a similar registry, The Gulf Registry of Acute Coronary Events (Gulf RACE) Zubaid M et al. [17].

\section{Patients and Methods}

The presented study was performed on 273 patients of both sexes .It is a prospective, registry of consecutive patients hospitalized with the final diagnosis of ACS in Sohag University Hospital, within 6 months from July to December 2012. The diagnosis of the different types of ACS and definitions of data variables were based on the American Cardiac College (ACC) clinical data standards. No control (cohort) was included. A confirmed written Consent was taken from all the Patients. The patients were selected for this study according to the following inclusion and exclusion criteria.

\section{Inclusion criteria}

a. Patients with final diagnosis of acute coronary syndrome.

b. Patients above 18 years.

\section{Exclusion criteria}

a) Patients admitted in the coronary care _unite (CCU) with final diagnosis other than ACS.

b) Patients under 18 years.

c) Patients on statin and other anti-dyslipidemic medications.

\section{For all the patients the following was done}

\section{Thorough history taking with special emphasis on}

i. History of ischemic heart disease, past history of myocardial infarction (MI), percutaneous coronary angiography(PCI)or coronary artery bypass graft (CABG).

ii. Age.

iii. Gender.

iv. Diabetes.

v. Hypertension.

vi. Smoking, current smoking was defined as smoking

vii. Cigarettes or water-pipe (sheesha) within 1 month of index admission.

viii.Family history of similar condition, a positive of CHD was defined as evidence of this history Family disease in a children, parent, sibling, before 55 years of age.

\section{Thorough clinical examination}

\section{A. General examination:}

a. Pulse.

b. Blood Pressure.

c. Body mass index (BMI).

d. Waist circumference.

\section{B. Local cardiac and chest examination.}

With special emphasis on signs of heart failure

\section{Investigations}

i. ECG.

ii. Total CK.

iii. CK_MB and Troponin.

iv. Lipid Profile especially:

a) Total Cholesterol.

b) HDL_C.

c) LDL_C.

d) Triglycerides.

e) VLDL_C.

v. Random blood glucose.

vi. Serum creatinin.

\section{Results}

\section{Demographic characteristics of the studied population}

The study include 273 patients admitted in Sohag University Hospital coronary care unit by final diagnosis ACS during 6 consecutive months from the period 1st July to 31th December 2012. As shown in Table 1 there were $160(58.6 \%)$ males and $113(41.4 \%)$ females. The mean age is $58.9+11.3$ (27_87)Ys. The 
total population was divided into 3 age groups as shown in Table 2 and Figure 1.

Table 1: Characteristics of the 273 Patients with Acute Coronary Syndrome in Sohag University Hospital.

\begin{tabular}{|c|c|}
\hline Total N(273) & \\
\hline $113(41.4 \%)$ & Female.N(\%) \\
\hline $58.9 \pm 11.3$ & Age Yrs \\
\hline $25.24 \pm 5.1$ & $\mathrm{BMI} \mathrm{cm} / \mathrm{m}^{2}$ \\
\hline $94 \pm 11.7$ & Waist circumference $\mathrm{Cm}$ \\
\hline $138(50.5 \%)$ & Previous IHD.N(\%) \\
\hline $78(28.6 \%)$ & Past history of MI.N(\%) \\
\hline $10(3.7 \%)$ & Past history of CABG.N(\%) \\
\hline $28(10.3 \%)$ & Past history of PCI.N(\%) \\
\hline $59(21.6 \%)$ & Family history of IHD.N(\%) \\
\hline $86(31.5 \%)$ & Smoker.N(\%) \\
\hline $108(39.6 \%)$ & Hypertension .N(\%) \\
\hline $89(32.6 \%)$ & DM.N(\%) \\
\hline $124(45.4 \%)$ & STEMI .N(\%) \\
\hline $149(54.6 \%)$ & NSTE_ACS.N(\%) \\
\hline $64(23.4 \%)$ & Renal impairement *.N\% \\
\hline $185.36 \pm 54.5$ & Total Cholesterol ,mean mg/dl \\
\hline $\begin{array}{c}115.4 \pm 47 \mathrm{mg} / \mathrm{dl} . \mathrm{N}(\%) 39 \\
(14.3 \%)<7\end{array}$ & LDL_C mean mg/dl \\
\hline $82(30 \%)$ & 70_100 mg/dl.N(\%) \\
\hline $152(55.7 \%)$ & >100 mg/dl.N(\%) \\
\hline $152.4 \pm 121.6$ & Triglyceride mean mg $\backslash \mathrm{dl}$ \\
\hline $177(64.8 \%)$ & $<150 \mathrm{mg} / \mathrm{dl} . \mathrm{N}(\%)$ \\
\hline $96(35.2 \%)$ & $\geq 150$ mg/dl.N(\%) \\
\hline \multicolumn{2}{|l|}{$\begin{array}{l}\text { Anti-dyslipidaemic initiatin } \\
\text { at hospital }\end{array}$} \\
\hline $227(83.2 \%)$ & Statin.N(\%) \\
\hline $21(7.7 \%)$ & Fiberates .N(\%) \\
\hline $25(9.2 \%)$ & Non.N(\%) \\
\hline
\end{tabular}

Table 2: Classification of the study population by age and gender differentiation.

\begin{tabular}{|c|c|c|c|c|c|}
\hline \multicolumn{2}{|c|}{ Age Group } & Male N & Female N & Total & Percentage \\
\hline A & $18-40$ Yrs & 13 & 6 & 19 & $7 \%$ \\
\hline B & $>40-65$ Yrs & 110 & 73 & 183 & $67 \%$ \\
\hline C & $>65$ Yrs & 37 & 35 & 34 & $26 \%$ \\
\hline \multicolumn{2}{|c|}{ Total } & 160 & 113 & 273 & $100 \%$ \\
\hline
\end{tabular}

\section{Classification of the study population by age and gender}

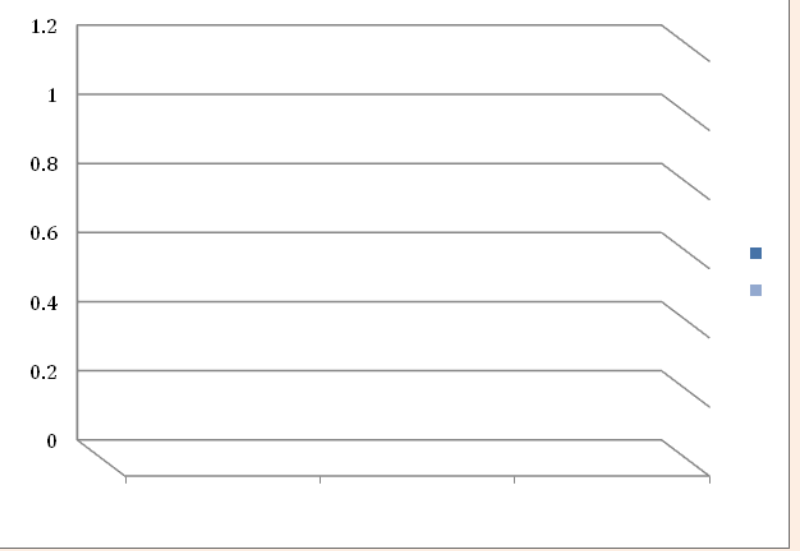

Figure 1: Classification of the study population by age and gender differentiation.

The prevalence of HDL_C level among the patients was low HDL_C level 200(73.3\%) $(<40 \mathrm{mg} / \mathrm{dl}$ for men and $<50 \mathrm{mg} / \mathrm{dl}$ for women) and satisfactory HDL_C level 73(26.7\%) (the level $\geq 40$ for men and $\geq 50$ for women), with mean BMI $25.2 \pm 5$ (15_41) kg/ $\mathrm{m}^{2}$ and with mean Waist Circumference $94 \pm 11.7\left(60 \_126\right) \mathrm{Cm}$. The study patients was associated with 108 (39.6\%) hypertension, D.M 89 (32.6\%), stroke $86(31.5 \%)$. Most of the patients had NSTE_ ACS 149 (54.6\%) associated with higher median total cholesterol $(185.4 \pm 54.4) \mathrm{mg} / \mathrm{dl}$, high mean Triglycerides $(152.4 \pm 121.6 \mathrm{mg} /$ dl) and mean LDL-C $(115.5 \pm 47 \mathrm{mg} / \mathrm{dl})$. Furthermore, majority of the patients initiated statin therapy at the hospital $227(83.2 \%)$ but only $27(7.7 \%)$ fenofibrate as shown in Table 1.

\section{Frequency of in hospital course and outcome in ACS patients in Sohag University Hospital}

As regard the hospital course and outcome, 177(64.8\%) improved, 40(14.7\%) suffered CHF, 15(5.5\%) suffered recurrent ischemic attacks, $4(1.5 \%)$ suffered re-infarction $6(2.2 \%)$ suffered Cardiogenic shock and 24(11.7\%) died as shown in Table 3 and Figure 2.

Table 3: Frequency of in hospital course and outcome in ACS patients in Sohag University Hospital.

\begin{tabular}{|c|c|c|}
\hline In-Hospital Course & Frequency (N) & Percent (\%) \\
\hline Improved & 177 & 64.8 \\
\hline CHF & 40 & 14.7 \\
\hline Reishaemia & 15 & 5.5 \\
\hline Reinfarction & 4 & 1.5 \\
\hline Cardiogenic Shock & 6 & 2.2 \\
\hline Death & 24 & 11.7 \\
\hline
\end{tabular}




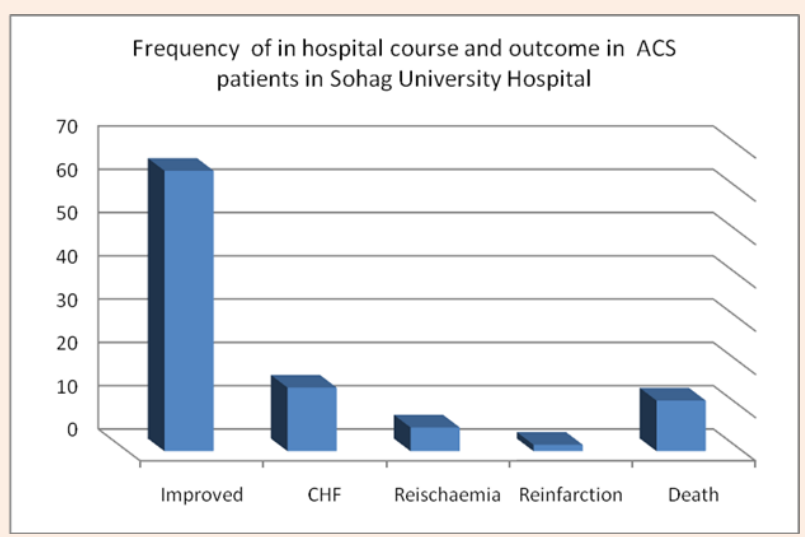

Figure 2: Frequency of in hospital course and outcome in ACS patients in Sohag University Hospital. $P$ value $=0.002$

Demographic and clinical characteristics of study population stratified by level of high density lipoprotein cholesterol

The patients were divided into two groups, as shown in Table 4, the low HDL-C group [group I], compared with the satisfactory HDL-C group [group II]. The low HDL-C group was associated with higher female gender (49.5\%vs.19.2\% p>0.001) see Figure 3 , and associated with higher median BMI (25.5 vs. $24.4 \mathrm{~kg} / \mathrm{m}^{2}$; $\mathrm{p}=.025)$, greater waist circumference (94vs.91 cm p=0.026), higher rate in diabetics (37.5 vs. $19.2 \%$; $\mathrm{p}=0.004$ ) see Figure 4 , and higher prevalence of low HDL-C in hypertensives (45 vs. $24.7 \%$; $=0.002$ ) see Figure 5, Low HDL-C group was also higher in ex-smokers (62.5\% vs. $37 \%$ p $<0.001)$ lower current smoking (28.1\% vs. $41.1 \% \mathrm{p}<0.001)$ see Figure 6, high in renal impairment (serum creatinin $>2 \mathrm{mg} / \mathrm{dl})(26.5 \%$ vs. $15.1 \%$; $\mathrm{p}=0.048)$ and higher in NSTE_ACS (57\% vs. $48 \%$ p=0.184).

Table 4: Demographic and Clinical Characteristics of Study Population Stratified by Level of High Density Lipoprotein Cholesterol.

\begin{tabular}{|c|c|c|c|c|}
\hline Variable & Group I & Group II & P Value & Significance \\
\hline Age Yrs & $58.9+14.4$ & $59.53+9.8$ & $0.001>$ & S \\
\hline Male. N\% & $59(36.9 \%)$ & $101(63.1 \%)$ & $0.001>$ & S \\
\hline Family h/o of CAD. N\% & $31(42.4 \%)$ & $107(53.5 \%)$ & 0.107 & N.S \\
\hline $\mathrm{BMI} \mathrm{kg} / \mathrm{m} 2$ & $24.4+5.1$ & $25.5+5.5$ & 0.025 & S \\
\hline Waist Circumference Median Cm & 91._+9.6 & $95+12.3$ & 0.026 & S \\
\hline Hypertension N \% & $18(24.7 \%)$ & $90(45 \%)$ & 0.002 & S \\
\hline Diabetes Mellitus N\% & $14(19.2 \%)$ & $75(37.5 \%)$ & 0.004 & S \\
\hline Smoker N\% & $30(41.1 \%)$ & $56(28 \%)$ & $0.001>$ & S \\
\hline Ex Smoker N\% & $27(37 \%)$ & $125(62.5 \%)$ & $<0.001$ & $\mathrm{~S}$ \\
\hline Past MI N\% & $21.9 \%) 16$ & $62(31 \%)$ & 0.142 & N.S \\
\hline Past PCI N\% & $7(9.5 \%)$ & $21(10.5 \%)$ & 0.82 & N.S \\
\hline Past CABG N\% & $2(2.7 \%)$ & $8(4 \%)$ & 0.62 & N.S \\
\hline Renal Impairement N\% & $11(15 \%)$ & $53(26.5 \%)$ & 0.025 & $\mathrm{~S}$ \\
\hline Blood Glucose mg/dl & $154+82$ & $183+95$ & 0.03 & S \\
\hline NSTE_ACS N\% & $38(52 \%)$ & $86(43 \%)$ & 0.184 & N.S \\
\hline STEMI_ACS N\% & $35(48 \%)$ & $114(57 \%)$ & 0.184 & N.S \\
\hline Statins N\% & $59(81 \%)$ & $168(84 \%)$ & 0.79 & N.S \\
\hline Other Antidyslipidaemic & $6(8.2 \%)$ & $15(7.5 \%)$ & 0.79 & N.S \\
\hline
\end{tabular}

Group 1 (satisfactory HDL_C)

Group II (low HDL_C)

$P$ value is significant if $<0.05$

$P$ value is highly significant if $<0.001$

Citation: Thabet NI, Hassanin HA, Kamal YM (2015) Study of High Density Lipoprotein Cholesterol among Patients with Acute Coronary Syndrome in Sohag University Hospital. J Cardiol Curr Res 2(5): 00073. DOI: 10.15406/jccr.2015.02.00073 


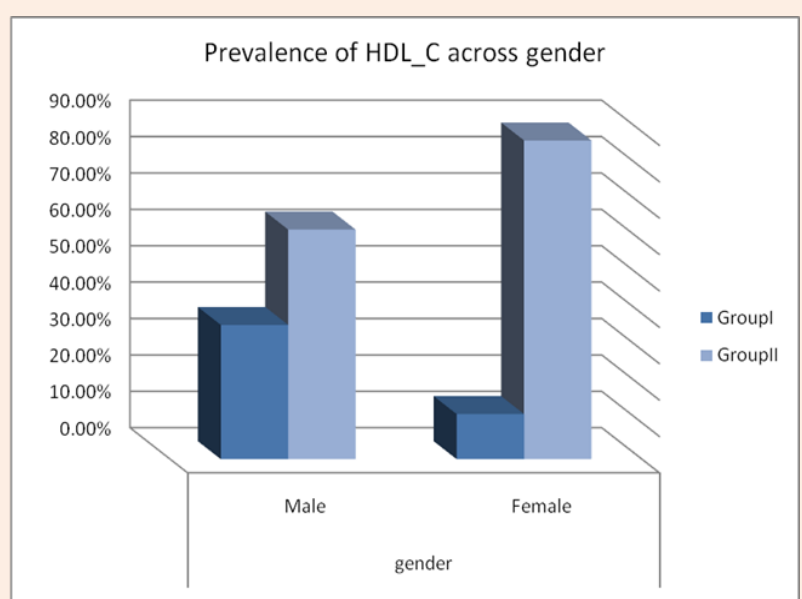

Figure 3: Prevalence of HDL-C across gender.

P value $<0.001$, Group I (satisfactory HDL_C), Group II (low HDL_C)

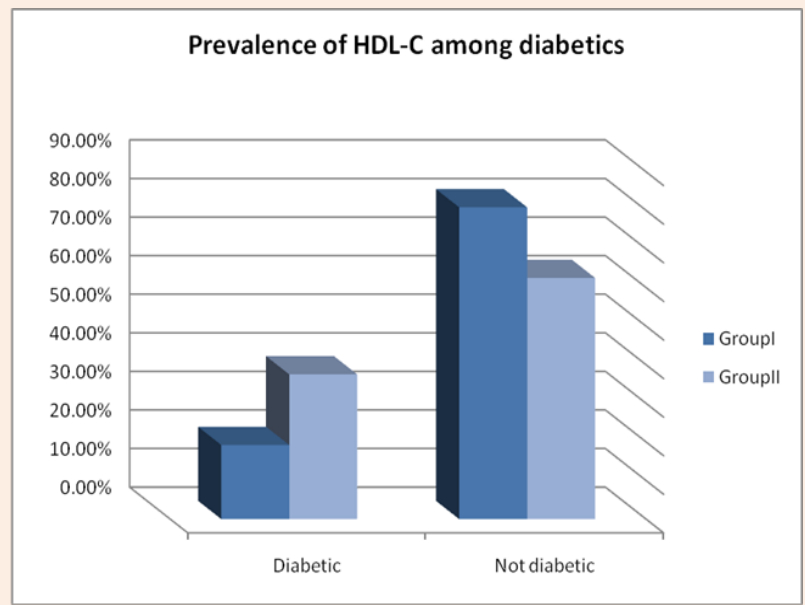

Figure 4: Prevalence of HDL-C among diabetics.

P value $=0.004$, group 1 (satisfactory HDL_C) Group II (low HDL_C)

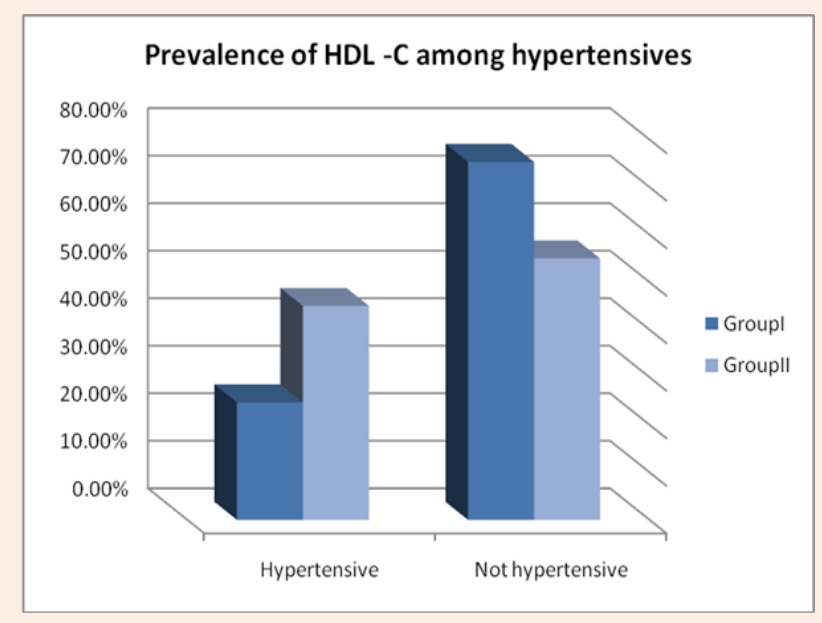

Figure 5: Prevalence of HDL-C among hypertensives.

P value $=0.002$, group 1 (satisfactory HDL_C) Group II (low HDL_C)

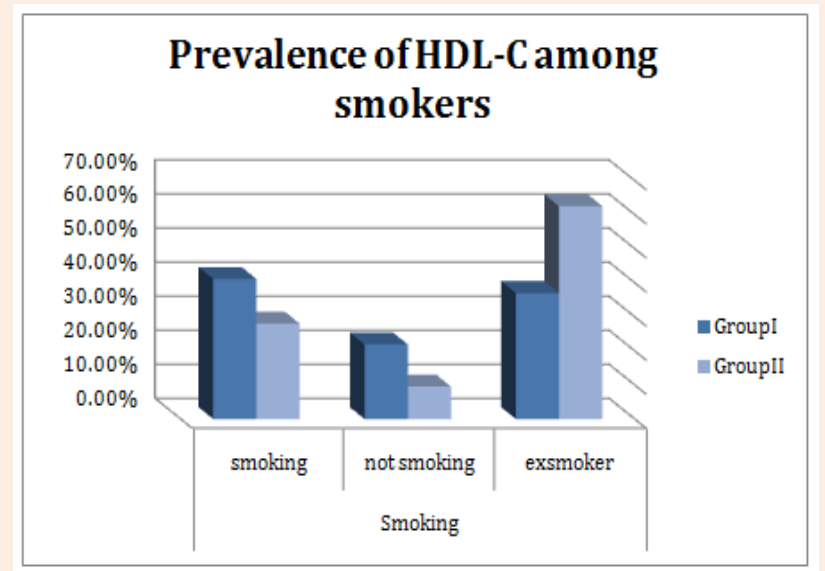

Figure 6: Prevalence of HDL_C among smokers.

P value $<0.001$, Group I (satisfactory HDL_C), Group II (low HDL_C)

\section{Lipid characteristics of study population stratified by level of high density lipoprotein cholesterol}

The low HDL-C group was associated with lower median LDL_C (113 vs. 120mg/dl, p=0.34) and higher mean Triglycerides (161 vs. $128 \mathrm{mg} / \mathrm{dl} \mathrm{p}=0.47)$ and higher mean VLDL_C (31 vs. $27 \mathrm{mg} / \mathrm{dl} \mathrm{p=0.054)} \mathrm{as} \mathrm{shown} \mathrm{in} \mathrm{Table} \mathrm{5,} \mathrm{Figures} 7 \& 8$.

Table 5: Lipid Characteristics of Study Population Stratified by Level of High Density Lipoprotein Cholesterol (HDL_C)(n=273).

\begin{tabular}{|c|c|c|c|c|}
\hline Lipid Profile & Group I 73 (26.7\%) & GroupII 200(73.3\%) & P Value & Significance \\
\hline Total Cholesterlol mg/dl. Mean & $200 \pm 47$ & $200 \pm 56$ & 0.025 & $\mathrm{~S}$ \\
\hline LDL_C Mean mg/dl & $120 \pm 45$ & $113 \pm 48$ & 0.34 & N.S \\
\hline$<70 \mathrm{mg} / \mathrm{dl}$ & $6(8.2 \%)$ & $33(16.5 \%)$ & 0.02 & $\mathrm{~S}$ \\
\hline $70-100 \mathrm{mg} / \mathrm{dl}$ & $22(30.2 \%)$ & $60(30 \%)$ & 0.02 & $\mathrm{~S}$ \\
\hline$>100 \mathrm{mg} / \mathrm{dl}$ & $45(61.6)$ & $107(53.5 \%)$ & 0.02 & $\mathrm{~S}$ \\
\hline Triglyceides Mean mg/dl & $128.3 \_+52$ & $161.3 \_+13$ & 0.47 & $\mathrm{~N} . \mathrm{S}$ \\
\hline$<150 \mathrm{mg} / \mathrm{dl}$ & $54(74 \%)$ & $123(61.5 \%)$ & 0.05 & $\mathrm{~S}$ \\
\hline$\geq 150 \mathrm{mg} / \mathrm{dl}$ & $19(26 \%)$ & $77(38.5 \%)$ & 0.05 & $\mathrm{~S}$ \\
\hline VLDL_C & $26.2++13$ & $30.8 \_+2$ & 0.05 & $\mathrm{~S}$ \\
\hline
\end{tabular}

Group II (low HDL_C), P value is significant if $<0.05$, $\mathrm{P}$ value is highly significant if $<0.001$ 


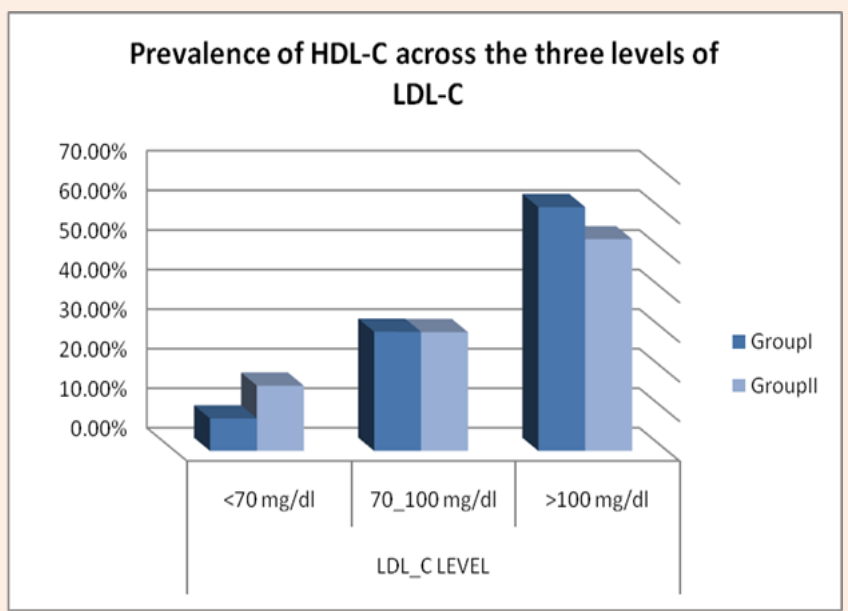

Figure 7: Prevalence of HDL-C across the three levels of LDL_C. $P$ value $=0.2$,

Group I (satisfactory HDL_C),

Group II (low HDL_C)

Patients with higher BMI, prior MI, diabetes mellitus, hypertension, renal impairment, ex-smokers, and were female more likely to have low HDL-C. However, those that were young, males, had higher LDL-C and lower triglycerides levels were more likely to be associated with satisfactory HDL-C.

The impact of HDL-C on in-hospital course and outcomes

The impact of HDL-C on in-hospital outcomes revealed that low HDL-C was associated with higher all in hospital morbidity and mortality, $\mathrm{CHF}(36(14.7 \%)$ vs. $4(5.5 \%) \mathrm{p}=0.01)$, recurrent ischemic attacks $(14(7 \%)$ vs. $1(1.4 \%) \mathrm{p}=0.01)$, reinfarction

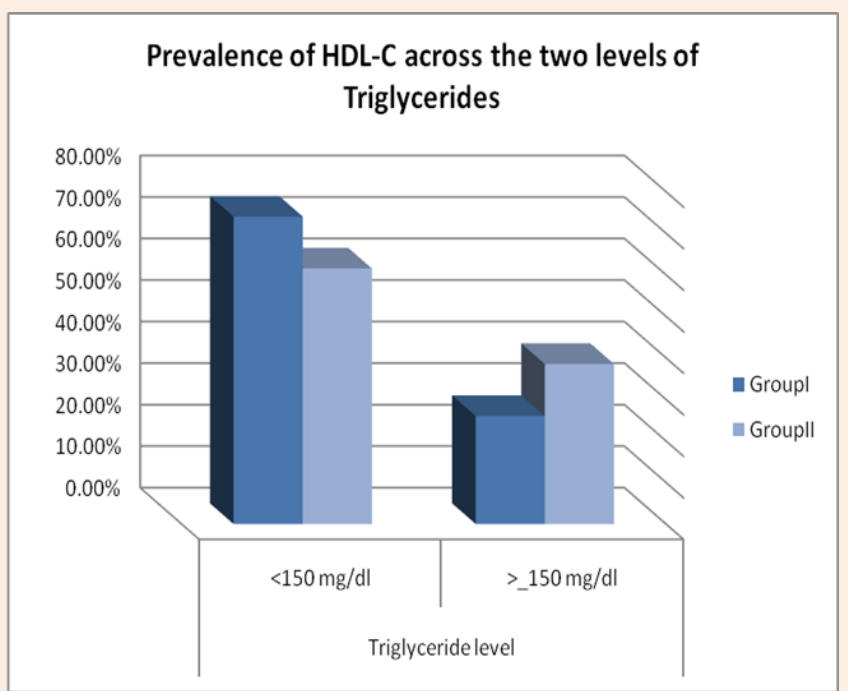

Figure 8: The prevalence of HDL-C across the two levels of Triglycerides $P$ value $=0.056$, Group I (satisfactory HDL_C), Group II (low HDL_C),

$(2(2.7 \%)$ vs. $2(1 \%) \mathrm{p}=0.29)$, cardiogenic shock $(6(3 \%)$ vs. $(0 \%)$ $\mathrm{p}=0.013)$ and Death $(16(14.2 \%)$ vs. $16(10 \%) \mathrm{P}=0.012)$ compared with the satisfactory HDL-C group as shown in Table 6.

\section{Cardiovascular risk factors across gender}

Women had higher rates of other cardiovascular risk factors than males, as shown in Table 7 and Figure 9 e.g.: DM $(46.9 \%$ vs. $22.5 \% \mathrm{P}<0.001)$, Hypertension $(48.7 \%$ vs. $33 \% \mathrm{p}=0.01)$ higher BMI $(25.9+6 \mathrm{~cm}$ vs. $24.8+4.3 \mathrm{p}=0.001)$ higher Waist Circumference ( $94.4 \mathrm{~cm}$ vs. $93.6 \mathrm{~cm} \mathrm{p}=.02$ ), higher family history of IHD $(24.8 \%$ vs. $19.4 \% \mathrm{p}=0.3)$ and higher mean total LDL_C (154.5 \pm 147 vs. $151 \pm 99.8 \mathrm{mg} / \mathrm{dl} \mathrm{p}=0.8$ ).

Table 6: In_hospital course and outcome of patients with ACS stratified by HDL_C level .

\begin{tabular}{|c|c|c|c|c|}
\hline In_Hospital Course and Outcome & Group I N(\%) & Group II N(\%) & P Value & Significance \\
\hline Improved & $57(78.1 \%)$ & $120(60 \%)$ & 0.02 & Significant \\
\hline $\mathrm{CHF}$ & $4(5.5 \%)$ & $36(18 \%)$ & 0.01 & Significant \\
\hline Reischaemia & $1(1.4 \%)$ & $14(7 \%)$ & 0.07 & Insignificant \\
\hline Reinfarction & $2(2.7 \%)$ & $2(1 \%)$ & 0.29 & Insignificant \\
\hline Cardiogenic Shock & $0(0.0 \%)$ & $6(3 \%)$ & 0.13 & Insignificant \\
\hline Death & $8(11 \%)$ & $24(12 \%)$ & 0.012 & Significant \\
\hline Total & $73(100 \%)$ & $200(100 \%)$ & & \\
\hline
\end{tabular}

Group I (satisfactory HDL_C),

Group II (low HDL_C),

$P$ value is significant if $<0.05$,

P value is highly significant if $<0.001$

Citation: Thabet NI, Hassanin HA, Kamal YM (2015) Study of High Density Lipoprotein Cholesterol among Patients with Acute Coronary Syndrome in Sohag University Hospital. J Cardiol Curr Res 2(5): 00073. DOI: 10.15406/jccr.2015.02.00073 
Table 7: Prevalence of cardiovascular risk factors across gender.

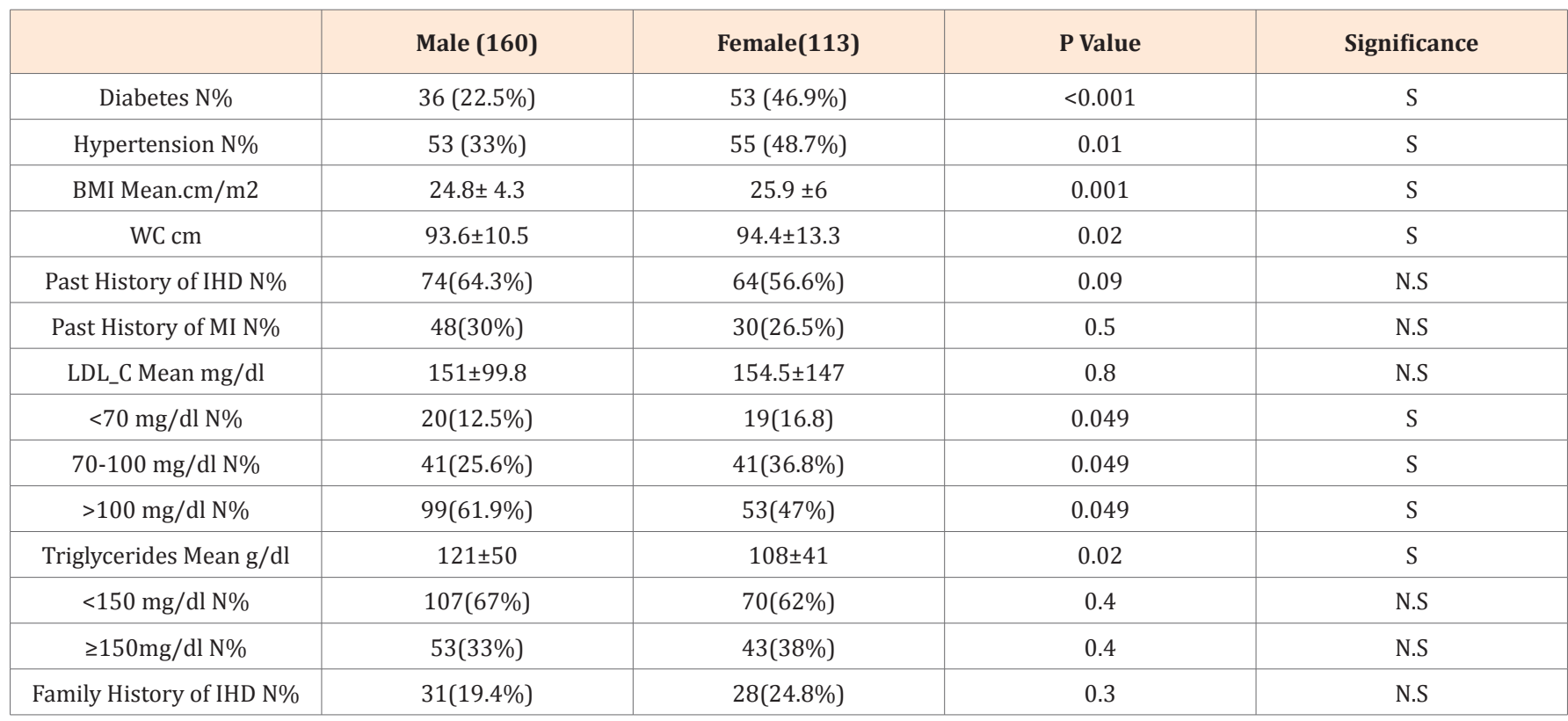

$P$ value is significant, $P$ value is highly significant if $<0.001$

BMI: Body Mass Index; WC: Waist Circumference; IHD: Ischaemic Heart Disease; MI: Myocardial Infarction; LDL: Low Density Lipoproteins.

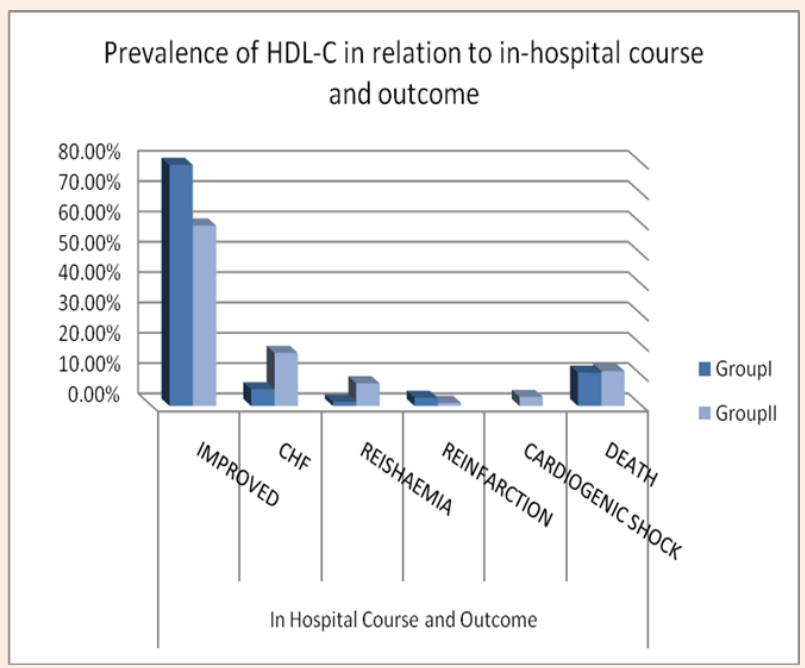

Figure 9: The prevalence of HDL_C among patients according to in hospital course and outcome.

P value $=0.009$, Group I (satisfactory HDL_C), Group II (low HDL_C)

Table 8: Frequency of in hospital course and outcome across gender.

\begin{tabular}{|c|c|c|c|}
\hline In Hospital Course and Outcome & Male N(\%) & Female N(\%) & P Value \\
\hline Impoved & $113(70.6)$ & $64(56.6 \%)$ & 0.03 \\
\hline CHF & $21(13.1 \%)$ & $19(16.8)$ & 0.4 \\
\hline Reischaemia & $8(5 \%)$ & $7(6.2)$ & 0.7 \\
\hline Reinfarction & $1(.6 \%)$ & $3(2.7 \% 0$ & 0.16 \\
\hline Cardiogenic Shock & $2(1.3 \%)$ & $4(3.5 \%)$ & 0.2 \\
\hline Death & $16(10 \%)$ & $16(14.2)$ & N.S \\
\hline Total & 160 & 113 & N.S \\
\hline
\end{tabular}

P value is significant if $<0.05$, P value is highly significant if $<0.001$, CHF: Congestive Heart Failure.

Citation: Thabet NI, Hassanin HA, Kamal YM (2015) Study of High Density Lipoprotein Cholesterol among Patients with Acute Coronary Syndrome in Sohag University Hospital. J Cardiol Curr Res 2(5): 00073. DOI: 10.15406/jccr.2015.02.00073 
Table 9: The frequency of the in hospital course and Outcome in relation the diagnosis.

\begin{tabular}{|c|c|c|c|c|}
\hline Variable & STEMI_ACS 124(45.4\%) & NSTE_ACS $149(54.6 \%)$ & $P$ value & Significance \\
\hline Improved & $92(74.2 \%)$ & $85(57 \%)$ & 0.003 & Significant \\
\hline CHF & $9(7.3 \%)$ & $31(20.8 \%)$ & 0.002 & Significant \\
\hline Reischaemia & $6(4.8 \%)$ & $9(6 \%)$ & 0.7 & Insignificant \\
\hline Rinfarction & $2(1.6 \%)$ & $2(1.3 \%)$ & 0.8 & Insignificant \\
\hline Cardiogenic shock & $3(2.4 \%)$ & $3(2 \%)$ & 0.8 & Insignificant \\
\hline Death & $11(8.9 \%)$ & $21(14 \%)$ & 0.18 & Insignificant \\
\hline
\end{tabular}

P value is significant if $<0.05$, P value is highly significant if $<0.001$

STEMI: ST Segment Elevation Myocardial Infarction; NSTE-ACS: Non ST Segment Elevation Acute Coronary Syndrome; CHF: Congestive Heart Failure.

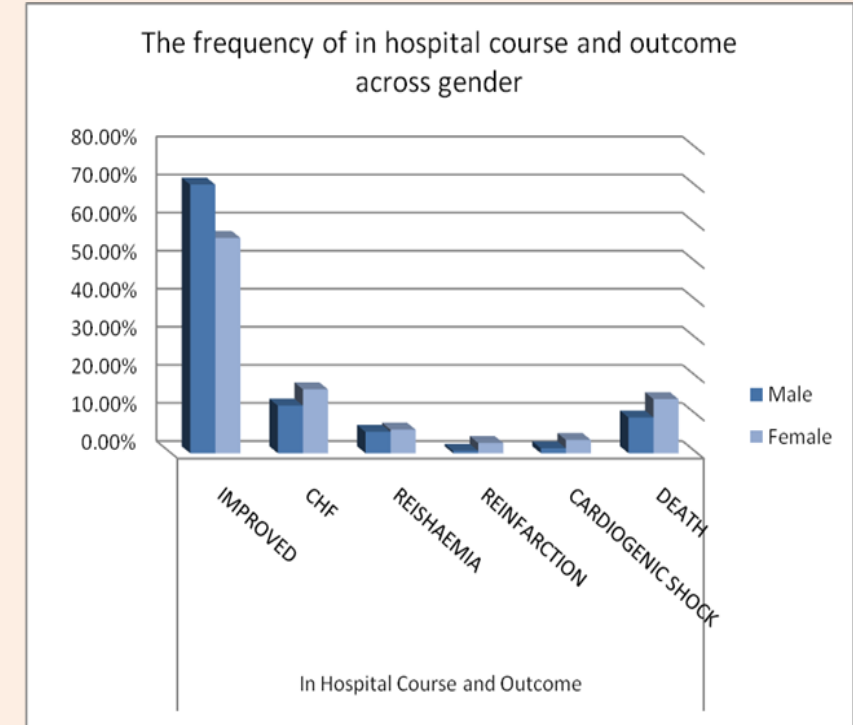

Figure 10: The frequency of in hospital course and outcome across Gender.

$P$ value $=0.17$

Women had higher in hospital mortality and morbidity than males as shown in Table 8 and Figure 10. Higher CHF (19(16.8\%)vs.21(13\%) $\mathrm{p}=0.4)$, Recurrent ischaemic attacks $(7$ (6.2\%)vs.8(5\%) p=0.7) Reinfarction (3(2.7\%)vs.1(.6\%) p=0.2), Cardiogenic Shock (4(3.5\%) vs. $2(1.3 \%) \mathrm{p}=0.2)$ and Death $(16(14.2 \%)$ vs. $16(10 \%) \mathrm{p}=0.3)$. Patients with diagnosis of NSTE ACS had higher rate of recurrent ischemia $(9(6 \%)$ vs. $6(4.8 \%)$ $\mathrm{p}=0.8)$ and $\mathrm{CHF}(31(21 \%)$ vs. $9(7.3 \%) \mathrm{p}=0.002)$ and higher rate of death $(21(14 \%)$ vs. $11(9 \%) \mathrm{p}=0.18)$ as shown in Table 9 and Figure 11.

\section{Discussion}

Ischemic heart disease is the main cause of disability and death in the most countries of the world. Despite the major improvements in diagnosis and treatment, one third of patients with ACS die. Half of these patients, within the first hour and before reaching to the hospital die. And two-thirds of those who survive do not ever fully recover and do not return to normal life Mirkhani H et al. [18].
The frequency of in hospital course and outcome in relation to the diagnosis

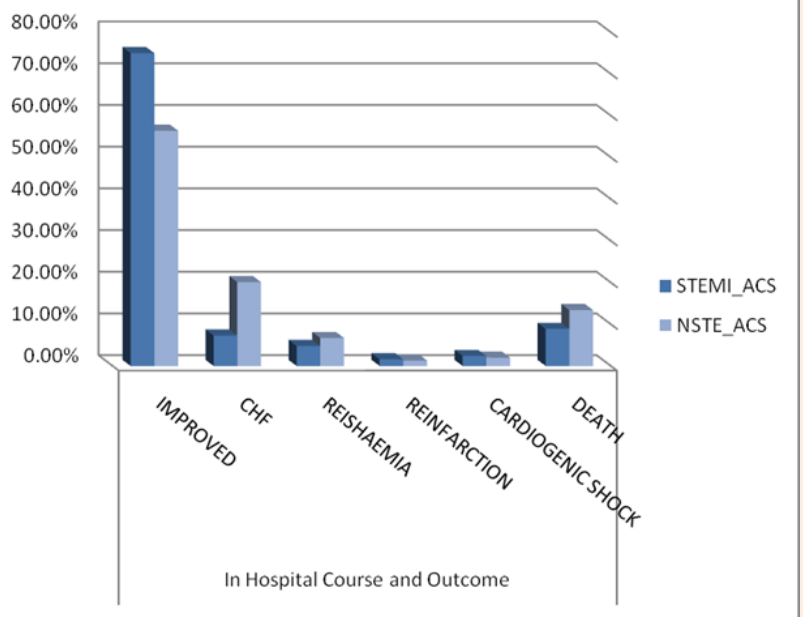

Figure 11: The frequency of the in hospital course and outcome in relation the diagnosis.

$P$ value $=0.02$

STEMI: ST Segment Elevation Myocardial Infarction; NSTE-ACS: Non ST Segment Elevation Acute Coronary Syndrome; CHF: Congestive Heart Failure.

The most common clinical manifestations of ACS are unstable angina (UA), non-ST-segment elevation myocardial infarction (NSTEMI) and ST-segment elevation myocardial infarction (STEMI). UA and NSTEMI are closely related conditions and called NSTE_ACS, both characterized by clinical symptoms suggestive of acute ischaemia (e.g. chest pain or discomfort), occurring de novo or rapidly increasing in frequency, duration and or intensity, with or without ST-segment depression or T-wave inversion on the Electrocardiogram (ECG). However, distinction between UA and NSTEMI is made by the absence or presence of circulating biomarkers for myocardial necrosis, respectively life Anderson JL et al. [19].

With few exceptions, low HDL is an independent risk factor for CAD in case-control and prospective observational studies. In contrast, high HDL levels are associated with longevity and are protective against the development of atherosclerotic disease. In the Framingham Study, risk for CAD increases sharply as HDL levels fall progressively below $40 \mathrm{mg} / \mathrm{dL}$ Castelli WP et al. [20]. Several mechanisms by which HDL protects against the development of 
CVD have now been identified. As outlined above, RCT is a wellestablished antiatherogenic function of HDL. A second important mechanism is the reduction of inflammation through the selective decrease of endothelial cell adhesion molecules that facilitate the binding of mononuclear cells to the vessel wall and promote lesion development Barter PJ et al. [21]. In this study two hundreds and seventy three patients was hospitalized with diagnostic criteria of ACS were studied to find out the prevalence of different levels of HDL_C in the studied patients and the impact of HDL_C on in-hospital outcome during hospital admission period in CCU ranging from 3 to 7 days.

We have demonstrated that about $200(73.3 \%)$ of studied patients had low HDL levels $(<40 \mathrm{mg} / \mathrm{dl}$ for men and $<50 \mathrm{mg} / \mathrm{dl}$ for women) and 73 (26.7\%) had satisfactory HDL level ( $\geq 40 \mathrm{mg} / \mathrm{dl}$ for men and $\geq 50 \mathrm{mg} / \mathrm{dl}$ for women)these result coincide with study on 6,266 patients, from middle east on 6 countries of the Gulf area Khalid AR et al. [22] showed the prevalence of low HDL(62\%) and satisfactory HDL (38\%). And coincide with a study from united states Rubins et al. [23] showed that in a population of 8,500 men at Veterans Affairs Medical Centers throughout the United States, $63 \%$ had low HDL-C. Contrary to the above reports which shows the very high prevalence of low HDL_C, There are other studies from other provinces of middle east reported high prevalence but to a lower extend study from Oman Ibrahim AZ et al. [24] on 1,458 patients showed the prevalence of low HDL_C ( $53 \%$ ). Also a study from Spain Xavier P et al. [25] on 367 patients also reported high prevalence of low HDL_C (57\%) but to a lower extend. And Sachdeva A et al. [26] study on 136,905 patient in USA, showed (55\%) of patients hospitalized with CAD had admission low HDL-C. And other similar study in USA by Wolfram M et al. [27] on 1,032 patients, showed a prevalence of low HDL_C (53.3\%).

In contrast, some studies showed low prevalence of low HDL. Arai et al. [28], in Japan on 249 patients reported low HDL (34\%) and high prevalence of satisfactory HDL(66\%). And Correia et al. [29] in Brazil on 97 patients reported low HDL(28\%) and high prevalence of satisfactory HDL $(72 \%)$. The higher percentage of low HDL_C and low percentage of satisfactory HDL_C in this study from all the studies abroad is due to the the small number of patients, bad eating habits, prevalence of obesity, poor sport culture, high prevalence of smoking either direct or passive and poor health culture. The low HDL-C group, compared with the satisfactory HDL-C, was associated with higher female gender (49.5\%vs 19.2\%; p <0.001), higher median BMI ( 25.5 vs. $24.4 \mathrm{~kg}$ / $\mathrm{m}^{2} ; \mathrm{p}=.025$ ), greater waist circumference ( 94 vs. $91 \mathrm{~cm} ; \mathrm{p}=0.026$ ), diabetes ( 37.5 vs. $19.2 \%$; $p=0.004$ ), hypertension ( 45 vs. $24.7 \%$; $\mathrm{p}=0.002$ ) higher renal impairment (serum creatinin $>2 \mathrm{mg} / \mathrm{dL}$ ) ( $26.5 \%$ vs. $15.1 \% \mathrm{p}=0.048$ ) and higher NSTE_ACS ( $57 \%$ vs. $48 \%$ $\mathrm{p}=.18$ ). Higher recurrent cardiovascular diseases, past history of IHD (53.5\% vs. $42.5 \%$ p value $=0.1)$, past history of MI $(31 \%$ vs. $22 \%$ p value $=0.14)$, past history of PCI $(10.5 \%$ vs. $9.6 \%$ p value $=0.8$ ) and past history of CABG ( $4 \%$ vs. $2.7 \%$ p value $=0.6$ ) all of this coincides with the study from middle east on 6 countries of the Gulf area Khalid AR et al. [22]. And in contrary to Xavier P et al. [25] which low HDL_C was more prevalent in males than females. The impact of HDL-C on in-hospital outcomes revealed that low HDL-C was associated with higher all in hospital morbidity and mortality e.g CHF, recurrent ischemic attacks, reinfarction, cardiogenic shock and death compared with the satisfactory HDL-C group. But the low HDL_C impact on in hospital outcome was significant for CHF and Death and this coincides with Khalid
AR et al. [22]. Low HDL-C is a component of metabolic syndrome and seen more commonly with obesity and diabetes [29,30]. In our analysis, patients with higher BMI, and diabetes mellitus, were more likely to have low HDL-C even after adjusting for other factors and this coincides with Khalid Al-Rasadi et al. [22]

Diabetic patients who have low HDL-C levels have cardiovascular event rates greater than those of diabetic patients with normal HDL-C levels levels Davidson MH et al. [30,31]. Kato et al. [32] showed that among the components of metabolic syndrome, abdominal obesity and low HDL-C levels were more frequently observed in patients with multiple, complex coronary lesions and this coincides with our study. Therefore, abdominal obesity and low HDL-C are likely to be key factors for coronary plaque vulnerability and may be associated with the poor clinical outcomes of ACS patients. Low HDL-C appears to be potentially a modifiable risk factor for patients with ACS. Optimization of lifestyle modifications by moderate weight loss (by 5-10\%) combined with exercise significantly decrease triglycerides and increase HDL-C levels, consequently improving cardiovascular risk. Van Gaal LF et al. [33] Low HDL-C has been shown to be associated with a higher risk of cardiovascular events and a greater burden of atherosclerosis, even among patients with controlled LDL-C, including those who are treated with a high dose statins Barter P et al. [34] and deGoma EM et al. [35].

In this context, showed that low levels of HDL-C remain significantly associated with increased cardiovascular risk despite statin treatment as a meta-analysis by Jafri et al. [36]. Moreover, a study by Correia et al. [29] demonstrated that low levels of HDL-C at admission in individuals with NSTE_ACS predicted recurrent inhospital events during hospitalization and LDL_C and triglycerides were not associated with cardiovascular events and this on the contrary to our study which show that low HDL_C in patients with NSTE_ACS is insignificantly associated with recurrent cardiovascular events except it is significantly associated with higher CHF. The high prevalence of low HDL in women, is likely related to the high prevalence of obesity and metabolic syndrome among women in Egypt Similarly a published Gulf RACE study on gender differences of cardiovascular risk factors, El-Menyar A et al. [37] showed that women had higher rates of other cardiovascular risk factors such as diabetes and hypertension and this coincides with our study and coincides with other study of GULF area by Khalid AR et al. [22]. Moreover in their study, women had higher adjusted in-hospital mortality compared with men. However, in our study, low HDL-C did not correlate with either mortality or cardiogenic shock in relation to gender, low HDL-C was in women insignificantly related to both mortality $(14.2 \%$ vs. $10 \% \mathrm{p}=0.3)$ and cardiogenic shock in females (3.5 vs. $1.3 \% \mathrm{p}=0.2$ ) and this coincides with Xavier P et al. [25]. But in contrast to Ibrahim AZ et al. [24] which Show significant relation between low HDL-C and all causes of in hospital morbidity and mortality in females.

\section{Study Limitations}

The limitations of a registry-type study apply, such as unidentified confounders which could influence the results. Furthermore, lipid levels may be partially affected during the acute phase of ACS and this could have influenced the estimation of low HDL-C levels Cannon CP et al. [38]. However, a recent study found little change in lipid levels measured serially in the first days of hospitalization for ACS de Lemos JA et al. [39]. The study 
was on a small governorate and in one hospital and consequently the number of patients is small in comparison to other studies.

\section{Conclusion}

This study demonstrated a high prevalence of low HDL_C levels in ACS patients in Sohag governorate in Upper Egypt and that this abnormality was more common in females than in males. Low HDL-C was common in diabetics, hypertensives, patients with renal impairment and in over weight and obese patients. Low HDL-C was significantly associated with higher all in-hospital mortality and CHF, but insignificantly associated with in-hospital mortality and cardiogenic shock in women. Although guidelines for LDL-C management in ACS are well established, treatment recommendations concerning HDL-C levels are not as rigorous or aggressive. Failure to recognize the prognostic value of low HDL-C in ACS may predispose these patients to higher risk of recurrent events and worse outcomes. Studies evaluating the clinical benefit of increasing HDL-C levels in patients with ACS are needed. It may be that small changes in HDL-C or those induced by currently available lipid lowering drugs are not effective.

\section{References}

1. Fox KA,Steg PG, Goodman SG,Anderson FA, et al. (2007) Decline in rates of death and heart failure in acute coronary syndromes,1999-2006. JAMA 297(17): 1892-1900.

2. Mortality and burden of disease (2012) World Health Organization.

3. Kontush A, Chapman MJ (2006) Functionally defective highdensity lipoprotein. A new therapeutic target at the crossroads of dyslipidemia, inflammation, and atherosclerosis. Pharmacol Rev 58(3): 342-374.

4. Expert Panel on Detection, Evaluation, and Treatment of High Blood Cholesterol in Adults (2001) Executive Summary of The Third Report of The National Cholesterol Education Program (NCEP) Expert Panel on Detection, Evaluation, And Treatment of High Blood Cholesterol In Adults (Adult Treatment Panel III). JAMA 285(19): 2486-2497.

5. Mora S, Buring JE, Ridker PM, Cui Y (2011) Association of highdensity lipoprotein cholesterol with incident cardiovascular events in women, by low-density lipoprotein cholesterol and apolipoprotein b100 levels: a cohort study. Ann Intern Med 155(11): 742-750.

6. Soudijn W, Van Wijngaarden I, Ijzerman AP (2007) Nicotinic acid receptor subtypes and their ligands. Med Res Rev 27(3): 417-433.

7. Meyers CD, Carr MC, Park S, Brunzell JD (2003) Varying Cost and Free Nicotinic Acid Content in Over-the-Counter Niacin Preparations for Dyslipidemia. Ann Intern Med 139(12): 996-1002.

8. Study: Boosting Good Cholesterol With Niacin Did Not Cut Heart Risks 2011.

9. When is treatment indicated for high cholesterol level?'

10. Richard N Fogoros (2011) How To Raise Your Hdl Levels.

11. Grundy SM, Cleeman JI, Daniels SR, Donato KA, Eckel RH, et al. (2005) American Heart Association; National Heart, Lung, and Blood Institute. Diagnosis and management of the metabolic syndrome: an American Heart Association/National Heart, Lung, and Blood Institute Scientific Statement. Circulation 112(17): 2735-2752.

12. Alberti KG, Eckel RH, Grundy SM, Zimmet PZ, Cleeman JI, et al. (2009) Harmonizing the Metabolic Syndrome A Joint Interim Statement of the International Diabetes Federation Task Force on Epidemiology and Prevention; National Heart, Lung, and Blood Institute;
American Heart Association's World Heart Federation; International Atherosclerosis Society; and International Association for the Study of Obesity. Circulation 120(16): 1640-1645.

13. Olsson AG, Schwartz GG, Szarek M, Sasiela WJ, Ezekowitz MD, et al. (2005) High-density lipoprotein, but not low-density lipoprotein cholesterol levelsinfluence short-term prognosis after acute coronary syndrome: results from the MIRACL trial. Eur Heart J 26(9): 890-896.

14. Wolfram RM, Brewer HB, Xue Z, Satler LF, Pichard AD, et al. (2006) Impact of low high-density lipoproteins on in-hospital events and oneyear clinical outcomes in patients with non-ST-elevation myocardial infarction acute coronary syndrome treated with drug-eluting stent implantation. Am J Cardiol 98(6): 711-717.

15. Tziakas DN, Chalikias GK, Kaski JC, Kekes A, Hatzinikolaou EI, et al. (2007) Inflammatory and anti-inflammatory variable clusters and risk prediction in acute coronary syndrome patients: a factor analysis approach. Atherosclerosis 193(1): 196-203.

16. Cordero A, Moreno-Arribas J, Bertomeu-Gonza'lez V, Agudo P, Miralles B, et al. (2012) Low levels of high-density lipoproteins cholesterol are independently associated with acute coronary heart disease in patients hospitalized for chest pain. Rev Esp Cardiol 65(4): 319-325.

17. Zubaid M, Rashed WA, Al-Khaja N, Almahmeed W, Al-Lawati J, et al. (2008) Clinical presentation and outcomes of acute coronary syndromes in the Gulf Registry of Acute Coronary Events (Gulf RACE). Saudi Med J 29(2): 251-255.

18. Mirkhani H, Hosseini M, Sanatkar M, Parvizi R, Radpour M, et al. (2005) social risk factors, behavior and lifestyle in patients with acute myocardial infarction. The Journal of Tehran Faculty of Medicine 3(63): 180-187.

19. Anderson JL, Adams CD, Antman EM, Bridges CR, Califf RM, et al. (2007) ACC / AHA 2007 guidelines for the management of patients with unstable angina / non-ST-Elevation myocardial infarction: a report of theAmerican College of Cardiology /American Heart Association Task Force on Practice Guidelines (Writing Committee to Revise the 2002 Guidelines for the Management of Patients With Unstable Angina / Non-ST-Elevation Myocardial Infarction) developed in collaboration with the American College of Emergency Physicians, the Society for Cardiovascular Angiography and Interventions, and the Society of Thoracic Surgeons endorsed by theAmerican Association of Cardiovascular and Pulmonary Rehabilitation and the Society for Academic Emergency Medicine. Jam Coll Cardiol 50(7): e1-e157.

20. Castelli WP, Garrison RJ, Wilson PWF, Abbott RD, Kalousdian S, et al. (1986) Incidence of coronary heart disease and lipoprotein cholesterol levels: the Framingham Study. JAMA 256(20): 2835-2838.

21. Barter PJ, Baker PW, Rye KA (2002) Effect of high-density lipoproteins on the expression of adhesion molecules in endothelial cells. Curr Opin Lipidol 13(3): 285-288.

22. Khalid Al-Rasadi, Ibrahim Al-Zakwani, Mohammad Zubaid, Amr Ali, Yasser Bahnacy, et al. (2011) Prevalence, Predictors, and Impact of Low High-Density Lipoprotein Cholesterol on in-Hospital Outcomes Among Acute Coronary Syndrome Patients in the Middle East. Open Cardiovasc Med J 5: 203-209.

23. Rubins HB, Robins SJ, Collins D, Iranmanesh A, Wilt TJ, et al. (1995) Distribution of lipids in 8500 men with coronary artery disease. Department of Veterans Affairs HDL Intervention Trial Study Group. AmJ Cardiol 75(17): 1196-1201.

24. Al-Zakwani Ibrahim, Sulaiman Kadhim, Al-Rasadi Khalid, Mikhailidis Dimitri P (2011) Prevalence of low high-density lipoprotein cholesterol (HDL-C) as a marker of residual cardiovascular risk among acute coronary syndrome patients from Oman. Curr Med Res Opin 27(4): 879-885. 
25. Pintó X, Millán J, Muñoz A, Corbella E, Hernández-Mijares A, et al (2010) A very high prevalence of low HDL cholesterol in Spanish patients with acute coronary syndromes. Clin Cardiol 33(7): 418-423.

26. Sachdeva A, Cannon CP, Deedwania PC, Labresh KA, Smith SC, et al (2009) Lipid levels in patients hospitalized with coronary artery disease: an analysis of 136905 hospitalizations in Get with the Guidelines. Am Heart J 157(1): 111-117.

27. Wolfram RM, Brewer HB, Xue Z, Satler LF, Pichard AD, et al. (2006) Impact of low highdensity lipoproteins on in hospital events and oneyear clinical outcomes in patients with non- ST-elevation myocardial infarction acute coronary syndrome treated with drug-eluting stent implantation. Am J Cardiol 98(6): 711-717.

28. Arai H, Hiro T, Kimura T, Morimoto T, Miyauchi K, et al. (2010) More intensive lipid lowering is associated with regression of coronary atherosclerosis in diabetic patients with acute coronary syndrome. Atheroscler Thromb 17(10): 1096-1107.

29. Correia LC, Rocha MS, Esteves JP (2009) HDL-cholesterol level provides additional prognosis in acute coronary syndromes. Int Cardiol 136(3): 307-314.

30. Davidson MH (2005) Reducing residual risk for patients on statin therapy: the potential role of combination therapy. Am J Cardiol 96(9A): 3K-13K.

31. Shepherd J, Barter P, Carmena R, Prakash Deedwania, Jean-Charles Fruchart, et al. (2006) Effect of lowering LDL cholesterol substantially below currently recommended levels in patients with coronary heart disease and diabetes: the Treating to New Targets (TNT) study. Diabetes Care 29(6): 1220-1226.

32. Kato M, Dote K, Naganuma T, Sasaki S, Ueda K, et al. (2010) clinical predictors of culprit plaque rupture assessed on intravascular ultrasound in acute coronary syndrome. Circ J 74(9): 1936-1942.

33. Van Gaal LF, Wauters MA, De Leeuw IH (1997) The beneficial effects of modest weight loss on cardiovascular risk factors. Int J Obes Relat Metab Disord 21(Suppl-1): S5-S9.

34. Barter P, Gotto AM, LaRosa JC, Maroni J, Szarek M, et al. (2007) Treating to New Targets Investigators. HDL cholesterol, very low levels of LDL cholesterol and cardiovascular events. N Engl J Med 357(13): 1301-1310.

35. deGoma EM, Leeper NJ, Heidenreich PA (2008) Clinical significance of high-density lipoprotein cholesterol in patients with low-density lipoprotein cholesterol. J Am Coll Cardiol 51(1): 49-55.

36. Jafri H, Alsheikh-Ali AA, Karas RH (2010) Meta-analysis: statin therapy does not alter the association between low levels of highdensity cholesterol and increased cardiovascular risk. Ann Intern Med 153(12): 800-808.

37. El-Menyar A, Zubaid M, Rashed W, Almahmeed W, Al-Lawati, et al. (2009) Comparison of men and women with acute coronary syndrome in six middle eastern countries. Am J Cardiol 104(8): 10181022.

38. Cannon CP, Braunwald E, McCabe CH, Rader DJ, Rouleau JL, et al. (2004) Intensive vs. moderate lipid lowering with statins after acute coronary syndromes. N Engl J Med 350(15): 1495-1504.

39. de Lemos JA, Blazing MA, Wiviott SD, Lewis EF, Fox KA, et al. (2004) Early intensive versus a delayed conservative simvastatin strategy in patients with acute coronary syndromes: phase $\mathrm{Z}$ of the $\mathrm{A}$ to $\mathrm{Z}$ trial. JAMA 292(11): 1307-1316. 